The characteristic behaviour of heterogeneous systems will thus be determined inter alia by both the number of polymer particles present and their total weight. Of these, the former will determine the rate at which radicals become occluded, while the latter will affect the efficiency of the polymer barrier in the aggregate.

The initial acceleration during thermal catalysed polymerizations, and the increase in after-effect with the extent of photopolymerization observed in the case of acrylonitrile, result from increases in both these factors. The rapid burst of reaction which ensues on heating a mixture of monomer and photopolymer prepared at low temperatures must be due to a sudden release of radicals occluded in the polymer; this may result from a physical break-up of the aggregates or from the increased probability of transfer to monomer. The retention of activity by the polymer over long periods at lower temperalures suggests that some radical ends are so completely occluded that transfer processes forming mobile radicals are practically negligible under these conditions. We are studying the possibilities of direct estimation of the concentration of these longlived radicals, and of their use as initiators for other reactions.

Values of the catalyst exponent exceeding 0.5 may arise from two causes. First, polymer formed at different rates of reaction will exert different accelerating effects; at lower rates the number of polymer particles present at any given degree of conversion will be less because more coalescence will already have occurred. Hence the probability of occlusion of radicals, and the consequent elevation of the rate, will be less at lower rates of reaction. Secondly, we may consider extreme cases of occlusion as spontaneous termination, and this again would increase the catalyst exponent. The actual value of the increase in the exponent above 0.5 will depend on the physical properties of the polymer, and the rate of reaction in the system under consideration; it may not be appreciable in some cases.

Abere, Goldfinger, Naidus and Mark ${ }^{5}$ observed that in the polymerization of styrene diluted with methanol the rate was unexpectedly high under conditions where the polymer was precipitated during reaction. They suggested that one factor producing this effect might be reduced termination due to inaccessibility of radicals within the precipitated phase. In this respect their concept was similar to ours; but they did not attempt to elucidate the general properties of heterogeneous systems. The effect of non-solvents on the polymerization of several monomers was described in greater detail in two valuable papers by Chapiro ${ }^{3}$, who considered the phenomena to be analogous to the gel effect in homogeneous systems.

Bengough and Norrish ${ }^{2}$ have suggested a mechanism based on chain transfer with precipitated dead polymer to account for the acceleration observed in vinyl chloride. Although this may participate at high conversions, it is insufficient to explain several of the results in our systems: for example, the catalytic effect of polymers prepared in the absence of catalyst when heated in the monomer.

It would appear that the phenomena encountered in heterogeneous polymerizations are too diverse to be explained in terms of either a simple gel effect, or immobilization of radicals by transfer to dead polymer. We consider that the ideas we have outlined are adequate to interpret our present knowledge of polymerization under heterogeneous conditions; their quantitative formulation will be difficult, because, as also concluded by Chapiro ${ }^{3}$, the usual stationarystate treatment does not apply.

1 Prat, Mem. Serv. chim. de l'Etat (Paris), 32, 319 (1946).

'Bengough and Norrish, Proc. Roy. Soc., A, 200, 301 (1950).

${ }^{3}$ Chapiro, J. Chim. Phys., 47, 747, 764 (1950).

- Burnett and Melville, Trans. Farad. Soc., 46, 976 (1950).

${ }^{\circ}$ Abere, Goldfinger, Naidus and Mark, J. Phys. Chem., 49, 211 (1945).

\section{I-MEV. DUAL-BEAM BETATRON IN THE CANTONAL HOSPITAL OF ZURICH}

A SERIES of articles dealing with the dual-beam 31-MeV. betatron produced by the Brown Boveri Company and with its applications to medicine, biology, physics and material testing has recently been published (Brown Boveri Review, issue of September-October 1951). One of the most interesting articles is that which describes the installation in the Radiological Department of the Cantonal Hospital of Zurich, under the direction of Prof. H. R. Schinz, which is used mainly for the treatment of deep-seated malignant tumours.

This betatron, installed in the winter of 1950 , possesses the novel feature of two electron guns arranged to inject in opposite directions at periods in the magnetic cycle separated $180^{\circ}$ in phase, and produces two beams displaced spatially by $180^{\circ}$ from a single platinum target. The installation is in the basement of the building and consists of an apparatus room, two treatment rooms, a control room, two dressing rooms, a laboratory and a workshop. The betatron and its associated equipment are housed in the apparatus room between the two treatment rooms, and only treatment cones defining the irradiated area and the patient-target distance are visible in the treatment rooms. By means of a mirror system, both treatment rooms can be viewed from the control desk situated in the control room. The controls have been designed to be mainly automatic so that the device can be operated by non-technical staff and with independent control of each beam.

Patients are shielded from stray radiation by some $1 \frac{1}{2}$ tons of lead attached directly to the betatron, and this reduces its intensity to less than 0.1 per cent of that in either of the main beams. Adjacent rooms are protected mainly by concrete walls about $70 \mathrm{~cm}$. thick, while the main beams are each absorbed in $2 \mathrm{~m}$. of concrete. Doors between the control and treatment rooms are of $4 \mathrm{~cm}$. of lead. These precautions reduce the stray radiation-level to a fraction of the tolerance dose of $6 \cdot 2 \mathrm{mr} . / \mathrm{hr}$.

The injection guns have a limited life of about a thousand hours, and to replace them it is necessary to remove the pumpless evacuated chamber ('donut') from the betatron. For this and other maintenance purposes, the complete betatron assembly weighing some $5 \frac{1}{2}$ tons is mounted on rails and can be wheeled from the narrow confines of the apparatus room into one of the treatment rooms. It requires about two days to change a 'donut' and carry out subsequent magnetic readjustments to obtain optimum output.

For the irradiation of patients, various field-sizes are required of uniform intensity over the entire irradiated field, and for this purpose there is a system of interchangeable resin-bonded lead-shot collimators with uniformity-correction filters of resin-bonded copper powder. In all, there are six 
different such collimator inserts, and to each of these two extensions or treatment cones can be attached to give patient-target distances of either 75 or $100 \mathrm{~cm}$. Thus twelve portals are available, some circular and some rectangular, with field areas ranging from 7 to $314 \mathrm{sq} . \mathrm{cm}$. The exposure times corresponding to a single treatment of $300 \mathrm{r}$. vary from 4 to $15 \mathrm{~min}$. Patients are supported on vertically and laterally adjustable tables and rest against the end of the treatment cone.

Operating experience obtained during the first five months shows that the apparatus meets satisfactorily the most exacting requirements of clinical service for a seven-hour daily working period. Forty patients have been treated during this time, and though, according to the report, a definite assessment will not be possible for some years, the results appear to be most promising.

D. A. LaYNe

\section{THE LIBRARY ASSOCIATION ANNUAL CONFERENCE}

$\mathrm{N}$ his presidential address to the Library Association conference at Bournemouth on April 29, Mr. L. R. McColvin suggested that, so far as the United Kingdom is concerned, there are now on the whole enough libraries, and the questions requiring consideration are whether the libraries are of the right type and satisfying the right kind of demand. It is the responsibility of librarians and library authorities, he said, to help make books a living force in the world to-day; fow individuals can possibly acquire for themselves more than a fraction of the books they could advantageously utilize. To do this, even more than for the special library, it is necessary for the public librarian to have clear ideas of the purposes he is to serve.

With this in mind, Mr. McColvin developed his philosophy of librarianship, arguing that the criteria of selection should be not primarily the quality of the book; the aim should be to supply the best each reader is willing to take. That is a step towards encouraging the fuller and more fruitful utilization of human resources, and, with regard to this, he referred to the need for a much better organization for the dissemination of scientific and technological information at all levels, from the research worker to the one-man business, the operative and the student. This is one way in which libraries can promote growth, and Mr. McColvin believes that it is even more important that they should promote faith and understanding. In this connexion he referred as illustration to the need to make adequate provision for public library services in the British Colonies and to the establishment by the Library Association of a committee to deal with such obligations.

In the concluding part of his address, Mr. McColvin insisted that each element in the library world should be in proper relation with all others which in any way share in its task of promoting the welfare and happiness of the community. The reference and technical and commercial departments of the public libraries in Britain should be able to call upon or refer inquirers to the libraries of research. The special library should see that its users are aware of the more general and comprehensive services of the public library; and all libraries associated with education, from the primary school to the training college, the technical institute and the university, should not only ensure that books are fully available and fully utilized for immediate educational processes, but also inculcate a life-long habit of wide reading undertaken in the spirit of search and inquiry. In Mr. McColvin's opinion, one of the most valuable features of postwar librarianship has been the advance towards genuine integration.

Although the majority of the papers presented at the conference were of no more than general or indirect interest to the scientific worker or technologist, a number of them will repay reading by him for the way in which they show how the work of the public library can contribute to the formation of an educated public opinion in which scientific and technical work can be most fruitfully prosecuted. An excellent example is Alderman C. P. Russell's paper, with its reference to the value of a good information service and the way in which the public library can encourage the wide reading that is an antidote to prejudice, complacency and apathy. Other papers of the same type include the annual lecture, delivered by Dr. L. Shores, dean of the School of Library Training and Service, Florida State University, with its reference to the function of the library in fostering free inquiry and overcoming both spiritual and material obstacles to such inquiry. Dr. Shores emphasized particularly the importance of availability and accessibility of material, especially from the point of view of research, and the need for a co-operative effort to accelerate the dissemination of information required for such purposes and reduce the interval between the discovery and the application of new knowledge.

This theme was developed further in several papers of some factual interest. These include W. B. Stevenson's account of Chaucer House and its library and information service, W. C. Watts's review of professional institutions and libraries, and $\mathrm{K}$. A. Mallaber's survey of the part played by government departments, and particularly the Board of Trade, in providing information for the business man. A. C. Townsend's account of the beginnings of the University and Research Section of the Library Association, 1928-52, and E. A. Baker's note on library research, may be put in the same group; but Councillor A. $\mathbf{H}$. Dilley's discussion of libraries and the business man is more a pointer to potentialities and opportunities of library service. The paper of most direct interest to both the man of science and technologist is undoubtedly that on technical college libraries, by L. L. Ardern, librarian of the College of Technology, Manchester. Without overburdening his paper with detail, Mr. Ardern marshalled sufficient factual information to provide convincing support for his argument as to the importance of such libraries in the expansion of both technical and higher technological education, and to display some of the grave deficiencies that are still to be found.

Quoting from the report on "Libraries in Technical Institutions", which was issued in 1938 jointly by the Association of Technical Institutions, the Association of Principals of Technical Institutions and the Association of Teachers in Technical Institutions, Mr. Ardern stated that only thirteen such colleges then possessed more than five thousand books, and of these only five possessed more than ten thousand. Only fifteen colleges spent more than $£ 200$ a year on books, binding and periodicals, and only twenty-one then employed full-time librarians-at salaries ranging from $£ 80$ to $£ 450$. Nor does Mr. Ardern adduce any evidence to suggest that in the interval 